\title{
An Analysis of the Components of Emotional Maturity and Adjustment in Combat Sport Athletes
}

\author{
Baljinder Singh Bal, Davinder Singh \\ Department of Physical Education, Guru Nanak Dev University, Amritsar, India
}

Email address:

bal_baljindersingh@yahoo.co.in (B. S. Bal)

To cite this article:

Baljinder Singh Bal, Davinder Singh. An Analysis of the Components of Emotional Maturity and Adjustment in Combat Sport Athletes. American Journal of Applied Psychology. Vol. 4, No. 1, 2015, pp. 13-20. doi: 10.11648/j.ajap.20150401.13

\begin{abstract}
The researchers of this study aim to know about the role of emotional maturity and adjustment in performance of combat sport athletes. To obtain data, the investigator had selected Seventy Five $(\mathrm{N}=75)$ male Inter college level combat sport athletes of 19 to 25 years of age to act as subjects. The purposive sampling technique was used to select the subjects. All the subjects, after having been informed about the objective and protocol of the study, gave their consent and volunteered to participate in this study. To measure the level of emotional maturity among subjects, Emotional Maturity Scale constructed by Singh and Bhargava's (1988) was administered. The level of Adjustment was measured by applying Adjustment Inventory prepared by A.K.P. Sinha \& R.P. Singh (1980). One way Analysis of Variance (ANOVA) was employed to find out the intragroup differences. Where F values were found significant LSD (Least Significant Difference) Post-hoc test was applied to find out the direction and degree of difference. For testing the hypotheses, the level of significance was set at 0.05 . In a nutshell it can be said that from the findings that insignificant differences were found among combat sport athletes (Boxing, Judo and Wrestling) on the sub-variables of Emotional Maturity i.e., Emotional Unstability, Emotional Regression, Social Maladjustment, Personality Disintegration, Lack of Independence and Emotional Maturity (Total). Concludingly from the findings that significant differences were present among combat sport athletes (Boxing, Judo and Wrestling) on the subvariables of Adjustment i.e., Social Adjustment, Emotional Adjustment and Total Adjustment. However, insignificant differences had been observed on the sub-variables; Home Adjustment, Health Adjustment and Educational Adjustment.
\end{abstract}

Keywords: Emotional Maturity, Adjustment, Combat Sport

\section{Introduction}

For enhancing performance and maximizing health benefits of athletes in combat sports psychological issues play a crucial role. Empirical evidence shows that mere participation in sports and combat art can prove to be psychological asset and also further helpful in lifelong activities regardless of whether the participation has been Competition oriented. (Matsumoto \& Konno, 2005). Combat sports (such as Boxing, Wrestling, Judo, and Taekwondo) are categorized into a series of weight classes that are intended to promote fair competition between rivals of equals stature and body mass. (Morton et al. 2010).

Combat players need a good combination of physical, physiological as well as psychological fitness in order to succeed. Of all the factors affecting sports performance, it seems that the most important one is the ability of the athlete to identify and assume the appropriate feeling required to perform his best when he needs to do. Whatever might be the level of skill, strength and experience of an athlete, his performance in the face of stiff competition will be largely influenced by his ability to assume the right emotion and attain an appropriate level of the emotional energy for optimum performance.

One's desire to excel in a specific area, be it sport or any other endeavor is driven by one's emotions and this process is facilitated or hindered by an individual's positive or negative emotions. Emotional maturity is the ability to experience, understand and express one's own deepest feelings in the most appropriate and constructive ways. As far as emotional maturity is concerned, it is a key factor for happiness in life without which an individual feels dependencies and insecurities in his life. Frank (1963) remarked that, Emotional maturity can be understood in terms of ability which helps to bear tension and frustration.

Walter (1974) elaborates that emotional maturity is a process in which the personality is continuously striving for 
greater sense of emotional health, both intra physically and intra-personally. The emotional aspect of maturity is the most important factor in the development of the comprehensive mature personality, especially for the gifted. This is the global factor of emotional maturity which is the strength to actualize individual abilities within the frame of social demands. In this rapid changing competitive sports scenario adjustment is a persistent feature of sportsperson's personality. Unless a person is not able to adjust himself to the environment he/she cannot develop his/her wholesome personality. A man of adjusting nature can lead a cheerful and wholesome life but a less adjusting nature always leads a depressed and unhealthy life. Adjustment is a process by which an individual learns certain ways of behaviour to cope with the situation which he/she attains through harmony with his/her environment. According to Drever (1952) Adjustment means the modification of behaviour to compensate for or meet special condition. In other words adjustment can be defined as the establishment of satisfactory relationship, as representing harmony conference adaptation or the like. It means the adjustment as the process of the finding and adopting models of behaviour suitable to the environment or to the changes in the environment. While considering the paramount importance of psychological variables with regard to combat sports the investigators focused to analyze the role of emotional maturity and adjustment in performance of combat sport athletes.

\section{Material and Methods}

\subsection{Selection of Subjects}

To obtain data, the investigator had selected Seventy Five

$(\mathrm{N}=75)$ male Inter college level combat sport athletes of 19 to 25 years of age to act as subjects. The purposive sampling technique was used to select the subjects. All the subjects, after having been informed about the objective and protocol of the study, gave their consent and volunteered to participate in this study.

Table 1. A break-up of selected sample

\begin{tabular}{lll}
\hline Sr. No & Combat Sport Athletes & Sample \\
\hline & Boxing & 25 \\
& Judo & 25 \\
& Wrestling & 25 \\
& & $\mathrm{~N}=75$ \\
\hline
\end{tabular}

\subsection{Tools}

To measure the level of emotional maturity among subjects, Emotional Maturity Scale constructed by Singh and Bhargava's (1988) was administered. To measure the level of Adjustment was measured by applying Adjustment Inventory prepared by A.K.P. Sinha \& R.P. Singh (1980).

\section{Statistical Analysis}

One way Analysis of Variance (ANOVA) was employed to find out the intra-group differences. Where $F$ values were found significant, LSD (Least Significant Difference) Posthoc test was applied to find out the direction and degree of difference. For testing the hypotheses, the level of significance was set at 0.05 .

\section{Results}

Table 2. Analysis of Variance (ANOVA) results with regard to Emotional Maturity among combat sport athletes (Boxing, Judo and Wrestling) on the subvariable Emotional Unstability

\begin{tabular}{lllll}
\hline Source of variance & Sum of Squares & df & Mean Square & F-ratio \\
\hline Between Groups & 38.140 & 2 & 19.070 & 1.092 \\
Within Groups & 2014.207 & 72 & 27.975 & .341 \\
Total & 2052.347 & 74 & & \\
\hline
\end{tabular}

*Significant at $0.05 \quad \mathrm{~F}_{0.05}(2,72)$

It can be observed from Table 2 that insignificant differences have been found with regard to the sub-variable Emotional Unstability among combat sport athletes (Boxing, Judo and Wrestling) as the P-value (Sig.) .341 was found higher than the 0.05 level of significance $(\mathrm{P}>0.05)$. Since $\mathrm{F}$ value was found insignificant, therefore, there is no need to apply post hoc test.

Table 3. Analysis of Variance (ANOVA) results with regard to Emotional Maturity among combat sport athletes (Boxing, Judo and Wrestling) on the subvariable Emotional Regression

\begin{tabular}{lllll}
\hline Source of variance & Sum of Squares & df & Mean Square & F-ratio \\
\hline Between Groups & 194.137 & 2 & 97.068 & 4.635 \\
Within Groups & 1507.810 & 72 & 20.942 & .113 \\
Total & 1701.947 & 74 & & \\
\hline
\end{tabular}

* Significant at $0.05 \mathrm{~F}_{0.05}(2,72)$

It can be observed from Table 3 that insignificant differences have been found with regard to the sub-variable Emotional Regression among combat sport athletes (Boxing,
Judo and Wrestling) as the P-value (Sig.) .113 was found higher than the 0.05 level of significance $(\mathrm{P}>0.05)$. Since Fvalue was found insignificant, therefore, there is no need to 
apply post hoc test.

Table 4. Analysis of Variance (ANOVA) results with regard to Emotional Maturity among combat sport athletes (Boxing, Judo and Wrestling) on the subvariable Social Maladjustment

\begin{tabular}{llllll}
\hline Source of variance & Sum of Squares & df & Mean Square & F-ratio & P-value Sig. \\
\hline Between Groups & 64.490 & 2 & 32.245 & 1.319 & .274 \\
Within Groups & 1760.177 & 72 & 24.447 & & \\
Total & 1824.667 & 74 & & & \\
\hline
\end{tabular}

*Significant at $0.05 \mathrm{~F}_{0.05}(2,72)$

It can be observed from Table 4 that insignificant differences have been found with regard to the sub-variable Social Maladjustment among combat sport athletes (Boxing, Judo and Wrestling) as the P-value (Sig.) .274 was found higher than the 0.05 level of significance $(\mathrm{P}>0.05)$. Since $\mathrm{F}$ value was found insignificant, therefore, there is no need to apply post hoc test.

Table 5. Analysis of Variance (ANOVA) results with regard to Emotional Maturity among combat sport athletes (Boxing, Judo and Wrestling) on the subvariable Personality Disintegration

\begin{tabular}{llllll}
\hline Source of variance & Sum of Squares & df & Mean Square & F-ratio & P-value Sig. \\
\hline Between Groups & 1.930 & 2 & .965 & .031 & .969 \\
Within Groups & 2208.257 & 72 & 30.670 & & \\
Total & 2210.187 & 74 & & & \\
\hline
\end{tabular}

*Significant at $0.05 \quad \mathrm{~F}_{0.05}(2,72)$

It can be observed from Table 5 that insignificant differences have been found with regard to the sub-variable Personality Disintegration among combat sport athletes (Boxing, Judo and Wrestling) as the P-value (Sig.) .969 was found higher than the 0.05 level of significance $(\mathrm{P}>0.05)$. Since F-value was found insignificant, therefore, there is no need to apply post hoc test.

Table 6. Analysis of Variance (ANOVA) results with regard to Emotional Maturity among combat sport athletes (Boxing, Judo and Wrestling) on the subvariable Lack of Independence

\begin{tabular}{llllll}
\hline Source of variance & Sum of Squares & df & Mean Square & F-ratio & P-value Sig. \\
\hline Between Groups & 5.780 & 2 & 2.890 & .174 & .841 \\
Within Groups & 1195.607 & 72 & 16.606 & & \\
Total & 1201.387 & 74 & & & \\
\hline
\end{tabular}

*Significant at $0.05 \mathrm{~F}_{0.05}(2,72)$

It can be observed from Table 6 that insignificant differences have been found with regard to the sub-variable Lack of Independence among combat sport athletes (Boxing, Judo and Wrestling) as the P-value (Sig.) .841 was found higher than the 0.05 level of significance $(P>0.05)$. Since Fvalue was found insignificant, therefore, there is no need to apply post hoc test.

Table 7. Analysis of Variance (ANOVA) results with regard to Emotional Maturity (Total) among combat sport athletes (Boxing, Judo and Wrestling)

\begin{tabular}{llllll}
\hline Source of variance & Sum of Squares & df & Mean Square & F-ratio & P-value Sig. \\
\hline Between Groups & 825.390 & 2 & 412.695 & 1.011 & .369 \\
Within Groups & 29378.690 & 72 & 408.037 & & \\
Total & 30204.080 & 74 & & & \\
\hline
\end{tabular}

*Significant at $0.05 \mathrm{~F}_{0.05}(2,72)$

It can be observed from Table 7 that insignificant differences have been found with regard to the variable Emotional Maturity (Total) among combat sport athletes (Boxing, Judo and Wrestling) as the P-value (Sig.) .369 was found higher than the 0.05 level of significance $(\mathrm{P}>0.05)$. Since F-value was found insignificant, therefore, there is no need to apply post hoc test. 
Table 8. Analysis of Variance (ANOVA) results with regard to Adjustment among combat sport athletes (Boxing, Judo and Wrestling) on the sub-variable Home Adjustment

\begin{tabular}{llllll}
\hline Source of variance & Sum of Squares & df & Mean Square & F-ratio & P-value Sig. \\
\hline Between Groups & 8.500 & 2 & 4.250 & 1.092 & .341 \\
Within Groups & 280.167 & 72 & 3.891 & & \\
Total & 288.667 & 74 & & & \\
\hline
\end{tabular}

*Significant at $0.05 \quad \mathrm{~F}_{0.05}(2,72)$

It can be observed from Table 8 that insignificant differences have been found with regard to the sub-variable Home Adjustment among combat sport athletes (Boxing, Judo and Wrestling) as the P-value (Sig.) .341 was found higher than the 0.05 level of significance $(\mathrm{P}>0.05)$. Since $\mathrm{F}$ value was found insignificant, therefore, there is no need to apply post hoc test.

Table 9. Analysis of Variance (ANOVA) results with regard to Adjustment among combat sport athletes (Boxing, Judo and Wrestling) on the sub-variable Health Adjustment

\begin{tabular}{llllll}
\hline Source of variance & Sum of Squares & df & Mean Square & F-ratio & P-value Sig. \\
\hline Between Groups & 15.843 & 2 & 7.922 & 1.697 & .190 \\
Within Groups & 336.077 & 72 & 4.668 & & \\
Total & 351.920 & 74 & & & \\
\hline
\end{tabular}

*Significant at $0.05 \quad \mathrm{~F}_{0.05}(2,72)$

It can be observed from Table 9 that insignificant differences have been found with regard to the sub-variable Health Adjustment among combat sport athletes (Boxing, Judo and Wrestling) as the P-value (Sig.) .190 was found higher than the 0.05 level of significance $(\mathrm{P}>0.05)$. Since Fvalue was found insignificant, therefore, there is no need to apply post hoc test.

Table 10. Analysis of Variance (ANOVA) results with regard to Adjustment among combat sport athletes (Boxing, Judo and Wrestling) on the sub-variable Social Adjustment

\begin{tabular}{lllll}
\hline Source of variance & Sum of Squares & df & Mean Square & F-ratio \\
\hline Between Groups & 68.057 & 2 & 34.028 & 5.565 \\
Within Groups & 440.290 & 72 & 6.115 & .006 \\
Total & 508.347 & 74 & & \\
\hline
\end{tabular}

*Significant at $0.05 \quad \mathrm{~F}_{0.05}(2,72)$

Table 10 presents significant differences with regard to the sub-variable Social Adjustment among combat sport athletes (Boxing, Judo and Wrestling) as the P-value (Sig.) .006 was found smaller than the 0.05 level of significance $(\mathrm{P}<0.05)$. Since the obtained F-value was found significant, therefore,

Least Significant Difference (LSD) post-hoc test was employed to study the direction and significance of differences between paired means among various combat sport athletes (Boxing, Judo and Wrestling) on the subvariable Social Adjustment. The results of LSD post hoc test have been presented in Table 10 (a).

Table 10 (a). Analysis of Least Significant Difference (LSD) post hoc test with regard to Adjustment among combat sport athletes (Boxing, Judo and Wrestling) on the sub-variable Social Adjustment

\begin{tabular}{llll}
\hline Group (A) & Group (B) & Mean Difference (A-B) & P-value (Sig.) \\
\hline Boxing & Judo (Mean=11.25) & -.97000 & .195 \\
(Mean=10.28) & Wrestling (Mean=12.50) & $-2.22000^{*}$ & .001 \\
Judo & Boxing (Mean=10.28) & .97000 & .195 \\
(Mean=11.25) & Wrestling (Mean=12.50) & -1.25000 & .084 \\
Wrestling & Boxing (Mean=10.28) & -2.22000 & .001 \\
(Mean=12.50) & Judo (Mean=11.25) & -1.25000 & .084 \\
\hline
\end{tabular}

* Significant at 0.05

A glance at table 10 (a) showed that the mean difference between boxing and judo group was found -.97000. The Pvalue (Sig.) .195 showed that judo group had exhibited better Social Adjustment though not significantly than their counterpart boxing group.
- The mean difference between boxing and wrestling group was found -2.22000. The P-value (Sig.) .001 revealed that the wrestling group had exhibited significantly better Social Adjustment than their counterpart boxing group. 
- The mean difference between judo and wrestling group was found -1.25000. The P-value (Sig.) .084 showed that wrestling group had exhibited better Social
Adjustment though not significantly than their counterpart judo group.

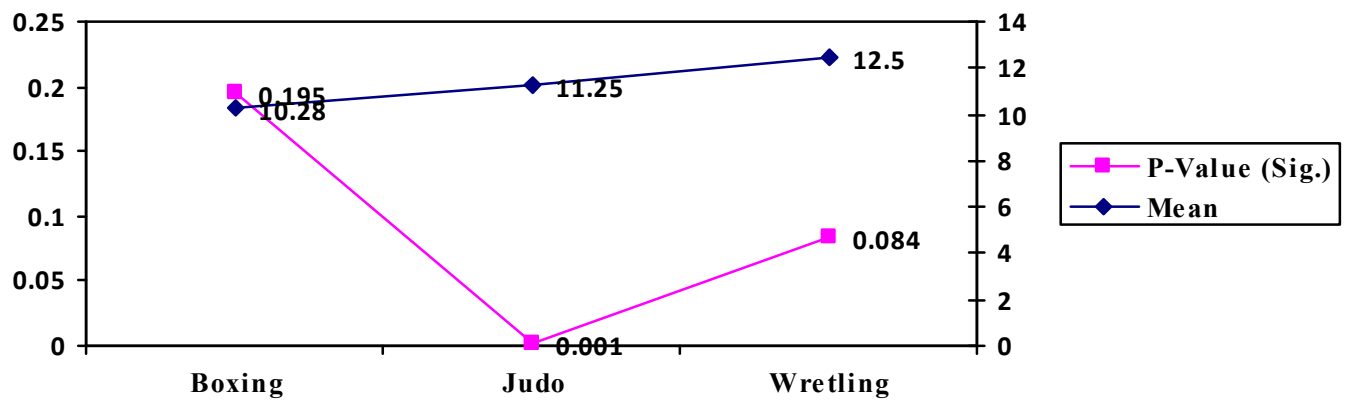

Figure 1. Graphical representation of mean scores and P-value Sig with regard to Adjustment among combat sport athletes (Boxing, Judo and Wrestling) on the sub-variable Social Adjustment

Table 11. Analysis of Variance (ANOVA) results with regard to Adjustment among combat sport athletes (Boxing, Judo and Wrestling) on the sub-variable Emotional Adjustment

\begin{tabular}{lllll}
\hline Source of variance & Sum of Squares & df & Mean Square & F-ratio \\
\hline Between Groups & 180.330 & 2 & 90.165 & 7.926 \\
Within Groups & 819.057 & 72 & 11.376 & .001 \\
Total & 999.387 & 74 & & \\
\hline
\end{tabular}

*Significant at $0.05 \quad \mathrm{~F}_{0.05}(2,72)$

Table 11 presents significant differences with regard to the sub-variable Emotional Adjustment among combat sport athletes (Boxing, Judo and Wrestling) as the P-value (Sig.) .001 was found smaller than the 0.05 level of significance $(\mathrm{P}<0.05)$. Since the obtained $\mathrm{F}$-value was found significant, therefore, Least Significant Difference (LSD) post-hoc test was employed to study the direction and significance of differences between paired means among various combat sport athletes (Boxing, Judo and Wrestling) on the sub-variable Emotional Adjustment. The results of LSD post hoc test have been presented in Table 11.

Table 11 (a). Analysis of Least Significant Difference (LSD) post hoc test with regard to Adjustment among combat sport athletes (Boxing, Judo and Wrestling) on the sub-variable Emotional Adjustment

\begin{tabular}{|c|c|c|c|}
\hline Group (A) & Group (B) & Mean Difference (A-B) & P-value (Sig.) \\
\hline \multirow{2}{*}{$\begin{array}{l}\text { Boxing } \\
\text { (Mean=17.32) }\end{array}$} & $\begin{array}{l}\text { Judo } \\
\text { (Mean=16.75) }\end{array}$ & .57000 & .575 \\
\hline & $\begin{array}{l}\text { Wrestling } \\
\text { (Mean=13.93) }\end{array}$ & $3.38667^{*}$ & .000 \\
\hline \multirow{2}{*}{$\begin{array}{l}\text { Judo } \\
\text { (Mean=16.75) }\end{array}$} & $\begin{array}{l}\text { Boxing } \\
\text { (Mean=17.32) }\end{array}$ & -.57000 & .575 \\
\hline & $\begin{array}{l}\text { Wrestling } \\
\text { (Mean=13.93) }\end{array}$ & $2.81667^{*}$ & .005 \\
\hline \multirow{2}{*}{$\begin{array}{l}\text { Wrestling } \\
\text { (Mean=13.93) }\end{array}$} & $\begin{array}{l}\text { Boxing } \\
(\text { Mean=17.32) }\end{array}$ & $-3.38667^{*}$ & .000 \\
\hline & $\begin{array}{l}\text { Judo } \\
(\text { Mean=16.75) }\end{array}$ & $-2.81667^{*}$ & .005 \\
\hline
\end{tabular}

*Significant at 0.05

- A glance at table 11 (a) showed that the mean difference between boxing and judo group was found .57000. The P-value (Sig.) .575 showed that boxing group had exhibited better Emotional Adjustment though not significantly than their counterpart judo group.

- The mean difference between boxing and wrestling group was found 3.38667. The P-value (Sig.) .000 revealed that the boxing group had exhibited significantly better Emotional Adjustment than their counterpart wrestling group.

- The mean difference between judo and wrestling group was found 2.81667. The P-value (Sig.) .005 revealed that the judo group had exhibited significantly better Emotional Adjustment than their counterpart wrestling 
group.

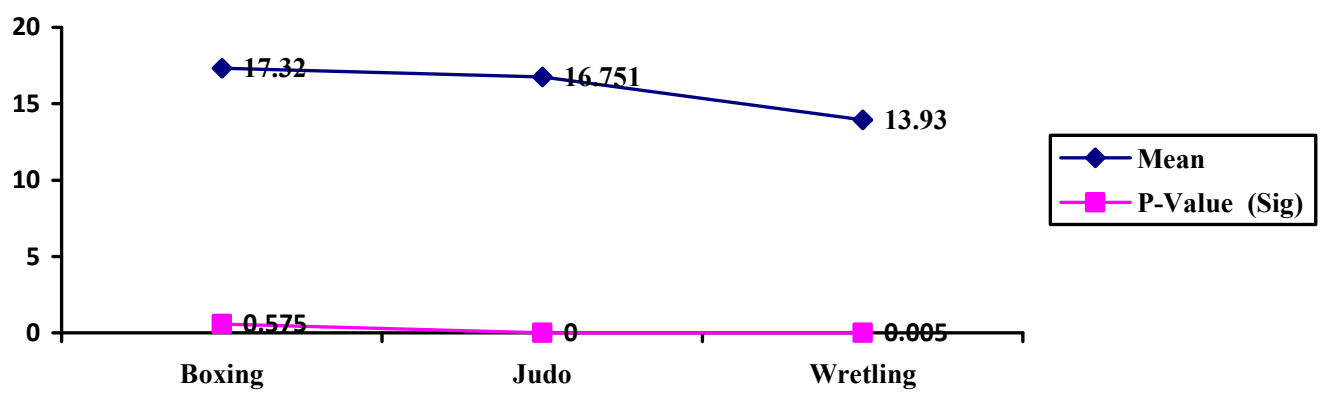

Figure 2. Graphical representation of mean scores and P-value Sig with regard to Adjustment among combat sport athletes (Boxing, Judo and Wrestling) on the sub-variable Emotional Adjustment

Table 12. Analysis of Variance (ANOVA) results with regard to Adjustment among combat sport athletes (Boxing, Judo and Wrestling) on the sub-variable Educational Adjustment

\begin{tabular}{llllll}
\hline Source of variance & Sum of Squares & df & Mean Square & F-ratio & P-value Sig. \\
\hline Between Groups & 24.500 & 2 & 12.250 & 1.995 & .143 \\
Within Groups & 442.167 & 72 & 6.141 & & \\
Total & 466.667 & 74 & & & \\
\hline
\end{tabular}

*Significant at $0.05 \quad \mathrm{~F}_{0.05}(2,72)$

It can be observed from Table 12 that insignificant differences have been found with regard to the sub-variable Educational Adjustment among combat sport athletes (Boxing, Judo and Wrestling) as the P-value (Sig.) .143 was found higher than the 0.05 level of significance $(\mathrm{P}>0.05)$. Since F-value was found insignificant, therefore, there is no need to apply post hoc test.

Table 13. Analysis of Variance (ANOVA) results with regard to Adjustment among combat sport athletes (Boxing, Judo and Wrestling) on the sub-variable Total Adjustment

\begin{tabular}{llllll}
\hline Source of variance & Sum of Squares & df & Mean Square & F-ratio & P-value Sig. \\
\hline Between Groups & 416.090 & 2 & 208.045 & 6.703 & .002 \\
Within Groups & 2234.577 & 72 & 31.036 & & \\
Total & 2650.667 & 74 & & & \\
\hline
\end{tabular}

*Significant at $0.05 \quad \mathrm{~F}_{0.05}(2,72)$

Table 13 presents significant differences with regard to the variable Total Adjustment among combat sport athletes (Boxing, Judo and Wrestling) as the P-value (Sig.) .002 was found smaller than the 0.05 level of significance $(\mathrm{P}<0.05)$. Since the obtained F-value was found significant, therefore, Least Significant Difference (LSD) post-hoc test was employed to study the direction and significance of differences between paired means among various combat sport athletes (Boxing, Judo and Wrestling) on the variable Total Adjustment. The results of LSD post hoc test have been presented in Table 13 (a).

Table 13 (a). Analysis of Least Significant Difference (LSD) post hoc test with regard to Total Adjustment among combat sport athletes (Boxing, Judo and Wrestling)

\begin{tabular}{llll}
\hline Group (A) & Group (B) & Mean Difference (A-B) & P-value (Sig.) \\
\hline $\begin{array}{l}\text { Boxing } \\
\text { (Mean=55.36) }\end{array}$ & $\begin{array}{l}\text { Judo } \\
\text { (Mean=50.95) }\end{array}$ & $4.41000^{*}$ & .010 \\
Jrestling & & .001 \\
Judo & (Mean=50.06) & $5.29333^{*}$ & .010 \\
(Mean=50.95) & $\begin{array}{l}\text { Boxing } \\
\text { (Mean=55.36) } \\
\text { Wrestling } \\
\text { (Mean=50.06) }\end{array}$ & $-4.41000^{*}$ & .585 \\
$\begin{array}{l}\text { Brexing } \\
\text { Wean=55.36) }\end{array}$ & .88333 & .001 \\
Mean=50.06) & $\begin{array}{l}\text { Judo } \\
\text { (Mean=50.95) }\end{array}$ & $-5.29333^{*}$ & .585 \\
\hline
\end{tabular}

\footnotetext{
* Significant at 0.05
} 
- A glance at table 13 (a) showed that the mean difference between boxing and judo group was found 4.41000 . The P-value (Sig.) .010 revealed that the boxing group had exhibited significantly better Total Adjustment than their counterpart judo group.

- The mean difference between boxing and wrestling group was found 5.29333. The P-value (Sig.) .001 revealed that the boxing group had exhibited significantly better Total Adjustment than their counterpart wrestling group.

- The mean difference between judo and wrestling group was found .88333. The P-value (Sig.) .585 showed that judo group had exhibited better Total Adjustment though not significantly than their counterpart wrestling group.

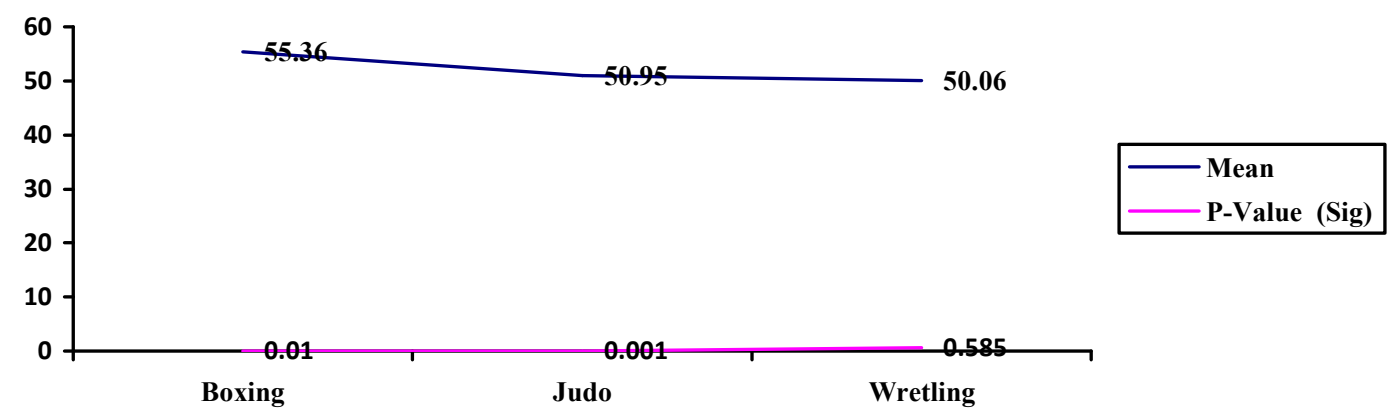

Figure 3. Graphical representation of mean scores and P-value Sig with regard to Total Adjustment among combat sport athletes (Boxing, Judo and Wrestling)

\section{Discussion}

The focus of this preliminary study was to examine the role of emotional maturity and adjustment in performance of combat sport athletes. A perusal at Analysis of Variance (ANOVA) with regard to Emotional Maturity that insignificant differences have been observed on the subvariables; Emotional Unstability, Emotional Regression, Social Maladjustment, Personality Disintegration, Lack of Independence and Emotional Maturity (Total). The result are contradict with other study conducted by Kiranben (2014) they indicate the working women significantly differ on Emotional maturity score as compared to non working women, working women have shown better Emotional Maturity compared to non working women. Rathee and Salh (2010) found that international players are significantly better in emotional maturity as compared to state players. Subbarayan and Visvanathan (2011) also found that the emotional maturity of college students is extremely unstable. Singh and Singh (2011) also found the status of emotional maturity is lower in Arts and Science students as compared to sports person. The above given findings and quoted studies clearly support that sports participation helps to improve emotional maturity of students. It is a well established fact that participation of sports develops group cohesiveness and harmony, psychological traits like mental alertness, social adjustability and personality traits within the participants. One also learns to control and regulate one's emotions while participating in competitions and as well as during practice sessions.

A perusal at Analysis of Variance (ANOVA) with regard to Adjustment among combat sport athletes (Boxing, Judo and Wrestling) revealed significant differences have been observed on the sub-variables; Social Adjustment, Emotional Adjustment and Total Adjustment. The above results might be due to the higher submissive and retiring abilities of the players. Similar trends have been reported by Biddulph (1954) they revealed that superior athletes showed higher levels of personal and social adjustment than less skilled athletes. Cronbach (1960) explained that the adjusted person is one who commits himself to socially desirable goals and uses his energies effectively in working towards them. According to Crow (1961) psychologically adjustment refers to an individual's characteristics or habitual under-standing of, reaction to, and manner of solving problem situations which he experiences. Gautam (1988) revealed that athletes were better adjusted and had lesser number of problems in social, emotional and total adjustment. It has been found that individuals who participate in sports activities generally have better life satisfaction and social adjustment which ultimately help them to lead a happy, healthy and harmonious life. Langner (1962) conducted a study on health adjustment among rural and urban college students and conclude that rural students face more problems than urban students, especially girls. Nanda (2001) reported that urban college students had better health than the rural college students. Sujatha et.al. (1993) studied adjustment problems among urban and rural college students and reported a significant difference in the social adjustment of urban and rural college students. Sulthana et.al. (1981) conducted a comparative study on social adjustment among urban and rural college students and reported that urban students were more socially adjusted as compared to rural students. A perusal at Analysis of Variance (ANOVA) tables with regard to adjustment level revealed insignificant differences among combat sport athletes (Boxing, Judo and Wrestling) on the sub-variable; 
Home Adjustment, Health Adjustment, Educational Adjustment. It can be summarise that combat sport athletes have unsatisfactory adjusted towards their home surroundings, health and low submissive and retiring abilities indicate their aggressive behavior while interacting with the people.

\section{Practical Application}

The study will be considerably helpful to comprehend the Emotional Maturity and Adjustment level existing among combat sport athletes (Boxing, Judo and Wrestling). The sports psychologists and coaches working with these areas will drive benefit from the findings of the present research and they can integrate the Emotional Maturity and Adjustment variables in their training schedule from the very initial stages.

\section{Conclusion}

Summarizing from the above findings we can say that insignificant differences were found among combat sport athletes (Boxing, Judo and Wrestling) on the sub-variables of Emotional Maturity i.e., Emotional Unstability, Emotional Regression, Social Maladjustment, Personality Disintegration, Lack of Independence and Emotional Maturity (Total). Concludingly from the above findings that significant differences were present among combat sport athletes (Boxing, Judo and Wrestling) on the sub-variables of Adjustment i.e., Social Adjustment, Emotional Adjustment and Total Adjustment. However, insignificant differences had been observed on the sub-variables; Home Adjustment, Health Adjustment and Educational Adjustment.

\section{References}

[1] Biddulph, L.G. (1954). Athletic Adjustment and the Personal and Social Adjustment of High School Boys. Research Quarterly, 25, 17.

[2] Cronbach, L.J. (1960). Essentials of Psychological Testing. Harper \& Bothers, New York.

[3] Crow, A. (1961). An Outline of Educational Psychology. Little fields; Adams \& Co. Peterson, New Jersey, 127-273.
[4] Drever. (1952). The effect of Participation in Selected Intramural Sports upon Physical Fitness Social and Emotional Adjustment of College Fraternity Man. Dissertation Abscart International, $275 \mathrm{~A}$.

[5] Frank. (1963). Nature and Human Nature. N.J. Rutgers University Press, New Brunswick, 101-102.

[6] Gautam, G.P. (1988). A Study of Effectiveness of Games and Sports as Related to the Development of High School Student's Personality, Attitude and Values. Unpublished PhD Thesis, Meerut University, Meerut.

[7] Kiranben, V. (2014). Emotional Maturity of Working and Non-Working Women. The International Journal of Indian Psychology, 2(1), 74-80.

[8] Lagner, V.K. (1962), Local and Sex difference in Health Adjustment of Students. Journal of Comm Guid res, 16(2), 200-235.

[9] Matsumoto, D., \& Konno, J. (2005). The Relationship between Adolescents' Participation in Judo, Quality of Life, and Life Satisfaction. Budogaku Kenkyu, 38(1), 13-26.

[10] Morton, J.P., Robertson, C., Sutton, L., \& MacLaren, D.P. (2010). Making the Weight: A Case Study from Professional Boxing. Int $J$ Sport Nutr Exerc Metab, 20, 80-85.

[11] Rathee, N.K., \& Salh, M.S. (2010). Exploring Cognitive Style and Emotional Maturity among Indian Handball Players Performing at Varying Level. Int. J. Sports Sci. Phys. Educ, 1(1), 26-33.

[12] Singh, J., \& Singh, S. (2011). Status of Emotional Maturity among Under Graduate College Students: A Comparative Analysis. Indian J. Sports Sci. Phys. Educ, 21, 9-18.

[13] Singh, Y., \& Bhargava, M. (1980). Manual for Emotional Maturity Construct and Standardized Emotional Maturity Scale. National Psychological Corporation, 4/230, Kachari gate, Agra, India.

[14] Sinha, A.K.P., \& Singh, R.P. (1995). Adjustment Inventory for College Students. Agra: National Psychological Corporation.

[15] Subbarayan, K., \& Visvanathan, G. (2011). A Study on Emotional Maturity of College Students. Recent Res. Sci. Technol, 3(1), 153-155.

[16] Sujatha, S., Goankar, V., Khadi, P.B., \& Katarki, P.A. (1993). Factors Influencing Adjustment among Adolescents. Ind. Psy. Rev, 40(1-2), 35-40.

[17] Walter, D., \& Simston, W.S (1974). Definition of Emotional Maturity. MH. Winter.58, 9-11. 